\title{
A PROMOÇÃO DA SAÚDE E O FORTALECIMENTO DE VÍNCULOS COMUNITÁRIOS POR MEIO DA ATIVIDADE FÍSICA: UM RELATO DE EXPERIÊNCIA
}

\begin{abstract}
Rodrigo Moraes Kruel
Mestrando em Saúde Coletiva, Universidade do Extremo Sul Catarinense, rmkpsico@hotmail.com

Mônica Martins Binatti

Profissional de Educação Física, Universidade do Extremo Sul Catarinense, monicabinatti@hotmail.com

Joni Marcio de Farias

Doutor, Universidade do Extremo Sul Catarinense, jmf@unesc.net
\end{abstract}

\section{RESUMO}

A preocupação com a saúde é um fator que pode ser associado à utilizaçáo do esporte ou da prática de atividade física para uma melhor qualidade de vida. Os benefícios da saúde pública obtidos ao praticar atividade física são potencialmente enormes, em virtude da alta prevalência de inatividade física (ACSM, 2003). De acordo com Nahas e Corbin (1992) e Guedes e Guedes (1995), existe forte associação entre a aptidão física ligada à saúde e o bom funcionamento orgânico, diminuindo os fatores de risco relacionados à doença. Isto seria uma justificativa a adesão do indivíduo à prática regulares de atividades físicas. A promoção da saúde desponta como "nova concepção de saúde" internacional em meados dos anos 70 , resultado do debate na década anterior sobre a determinação social e econômica da saúde e a construção de uma concepção 
não centrada na doença (HEIDMANN, 2012). O objetivo da Política Nacional da Saúde é "promover a qualidade de vida e reduzir vulnerabilidades e riscos à saúde relacionados aos seus determinantes e condicionantes - modos de viver, condiçôes de trabalho, habitação, ambiente, educação, lazer, cultura, acesso a bens e serviços essenciais”. Os eixos prioritários de ação da Política Nacional da Promoção da Saúde são: alimentação saudável, prática corporal/atividade física, prevenção e controle do tabagismo, redução da morbimortalidade em decorrência do uso abusivo de álcool e outras drogas, redução da morbimortalidade por acidentes de trânsito, prevenção da violência estímulo à cultura de paz e promoção do desenvolvimento sustentável (MALTA et al., 2014). Dentro de todo este contexto, em 2008, as Secretarias Municipais de Educação e de Assistência Social de Lauro Müller investiram em um projeto chamado Basquete Lauro Müller, no qual a modalidade esportiva serve como possibilidade de fortalecimento de vínculos comunitários e promoção da saúde. A Comissão Municipal de Esporte de Lauro Müller também contribuiu para que este projeto fosse realizado com efetividade. A ausência de lazer alternativo nas comunidades é notável em todos os lugares. O Projeto Basquetebol Lauro Müller vem para amenizar esta carência, possibilitando a prática do basquetebol para toda comunidade do Barro Branco. Além da própria prática esportiva, que conta com estagiários de Educação Física, sempre supervisionados pela professora de Educação Física da escola contemplada, o psicólogo do Centro de Referência de Assistência Social (CRAS) acompanha a escola, a comunidade e os participantes do projeto. O objetivo do projeto é de promoção da saúde e de fortalecimento de vínculos comunitários, facilitando os processos de adesão às atividades físicas, além de combater a ociosidade e ofertar lazer ativo para crianças, adolescente e para quem se interessar. A iniciação esportiva configura-se ainda como um campo privilegiado da intervençáo do psicólogo. É crescente o número de crianças envolvidas em atividades esportivas pedagógicas e competitivas. A prática esportiva tem sido apontada como um importante elemento na educação e socialização de crianças e jovens. Dentre as muitas razóes alegadas para o desenvolvimento esportivo de crianças e jovens, encontram-se o divertimento, o aperfeiçoamento de habilidades e a convivência com amigos (RUBIO, 2007). O basquetebol (popularmente conhecido como 
basquete) surgiu no ano de 1891, nos Estados Unidos. Seu criador foi James Naismith, professor de Educação Física da Associação Cristã de Moços de Springfield (Massachusetts - EUA), o basquete tem suas origens nas mais antigas sociedades, porém, na sua forma atual, é conhecido desde 1891 (VIEIRA; FREITAS, 2006). Frente a isso, primeiramente o psicólogo entrou em contato com a escola para verificar a viabilidade e o interesse dos alunos, posteriormente foram convidados alunos a partir do $4^{\circ}$ ano. Os primeiros encontros no ano de 2008 foram em um clima de desconfiança, pois a prática do basquetebol era desconhecida. As atividades são organizadas pelo psicólogo e por um estagiário de Educação Física, englobando intervençóes como: orientaçóes psicossociais, rodas de conversa com temas de interesse do público-alvo, aulas e iniciação ao basquetebol, torneios e festivais de basquetebol e participação nos Jogos Escolares Catarinenses (JESC). Participam do projeto crianças e adolescentes de todas as idades, e as turmas são divididas conforme a faixa etária. No país do futebol, no começo houve certa resistência em relação à prática do basquetebol, pois se entende que esta modalidade não é muito praticada no Brasil e a grande mídia não a valoriza. O local dos encontros é em uma quadra de cimento descoberta, em frente a escola. Aos fundos da escola há um ginásio, porém está interditado por falta de segurança na sua estrutura. Percebemos, portanto, que a quadra é um fator desestimulante para participação, sem contar que, dependendo das condiçóes climáticas, ficam inviáveis os encontros. As Secretárias Municpais de Educação e de Assistencia Social investem na infraestrutura e logística do Projeto Basquete Lauro Müller, adquirindo bolas de basquetebol, camisas de passeio com a logo do projeto, uniformes específicos para a prática de basqutebol, lanches e transporte para jogos ou passeios recerativos. A Secretaria Municipal de Sáude está sempre presente, por meio da Unidade Básica de Sáude do Barro Branco, nos casos de lesões, além de realizar rodas de conversa sobre sexualidade, drogas, higiene, cuidados com o corpo, planejamneto familiar, gravidez precoce, entre outros temas. No ano de 2008, o time de basquete formado pelo projeto começou a representar a Escola Municipal Emília Mamede Soares. Já na primeira participação, houve medalha de parta; em 2009, medalha de ouro e vaga garantida na fase estadual em Florianópolis. Na capital do Estado, os resultados não foram positivos, mas a experiência adquirida nessa viagem desencadeou um interesse muito forte 
pelo basquetebol. A participação da família, escola e comunidade é o diferencial do projeto, pois busca estimular, de maneira equilibrada, a participação efeitva de crianças e adolescentes. O projeto náo tem como objetivo só o desenvolvimento do desempenho esportivo, mas o desenvolvimento das capacidades sociais, bem como o desenvolvimento saudável por meio da atividade física. Em relação à escola, ficou evidente a melhora do comportamento e do rendimento escolar, de forma geral dos participantes. A diretora, professores e funcionários da escola também apoiam o projeto, colocando-se sempre à disposição. Percebemos, portanto, que eles entendem que este projeto é muito importante para vida destes indivíduos. Nesses anos, aproximadamente 200 crianças e adolescentes tiveram contato com o basquetebol, muitos resultados positivos foram evidenciados: medalhas, viagens para jogos, viagens recretaivas, festivais de basquete e treinos semanais que acontecem até os dias de hoje, além de promover saúde e forlecer vínculos comunitários. Atualmente, o projeto atende 30 crianças e adolescentes de ambos os sexos. Para finalizar, um fato relevante constatado foi que adolescentes que começaram no projeto em 2008, hoje, são adultos e continuam jogando basquete. Consideramos que a atividade física promovida por meio do Projeto Basquete Lauro Müller valorizou a inserção social de crianças e adolescentes da comunidade do Barro Branco, além de oferecer uma alternativa de lazer saudável, reduzindo a ociosidade e a inatividade física. Observamos também que o esporte proporcionou a superação de limitaçóes emocionais, como a melhora da autoestima dos participantes e o fortalecimento do vínculo familiar e comunitário.

Palavras-chave: Promoção da Saúde; Atividade Física; Crianças e Adolescentes; Comunidade.

\section{REFERÊNCIAS}

ACSM. Diretrizes do ACSM para os testes de esforço e sua prescrição. 6. ed. Rio de Janeiro: Guanabara Koogan, 2003.

GUEDES, D. P.; GUEDES, J. E. R. P. Atividade física, aptidão física e saúde. Revista Brasileira de Atividade Física e Saúde, Brasília, v. 1, n.1, p.18-35, 1995. 
HEIDEMANN, I. T. S. B. Promoção da saúde e qualidade de vida: concepçôes da Carta de Ottawa em produção científica. Ciência, Cuidado e Saúde, Maringá, v.11, n.3, p.613-619, 2012.

MALTA, D. et al. Política Nacional de Promoção da Saúde: descrição da implementação do eixo atividade física e práticas corporais, 2006 a 2014. Revista Brasileira de Atividade Física e Saúde, Brasília, v.19, n.3, p.286-299, 2014.

NAHAS, M. V.; CORBIN, C.B. Aptidão Física e Saúde nos programas de educação física. Revista Brasileira de Ciências e Movimento, Brasília, v.8, n.2, p.14-24, 1992.

RUBIO, K. Da psicologia do esporte que temos à psicologia do esporte que queremos. Revista Brasileira de Psicologia do Esporte, Brasília, v.1, n.1, p.1-13, 2007.

VIEIRA, S.; FREITAS, A. O que é basquete: história, regras e curiosidades. Rio de Janeiro: Casa da Palavra: COB, 2006. 